\title{
Photoelectrochemical Response of Cyanine Dye-Containing Langmuir-Blodgett Films Prepared by Ion Complex Technique
}

\author{
Masatsugu SHIMOMURA* and Takehiko SHIMAMURA
}

Received June 4, 1992 ; Accepted August 26, 1992

\section{INTRODUCTION}

Since Kuhn and Möbius ${ }^{1)}$ found effective photoinduced electron transfer by the Jaggregates of cyanine dyes in Langmuir-Blodgett (LB) films, many sorts of dye-containing LB films have been prepared as a photoelectrochemical converter of light energy ${ }^{2)}$. The ioncomplex technique is useful to prepare hybrid LB films of amphiphilic monolayers and counter charged electrolytes, such as charged polymers $\left.{ }^{3}\right)$ and ionic dye molecules. Some cationic cyanine dyes without long alkyl chain formed $J$ aggregates at the interface of an arachidic acid monolaye ${ }^{4,5}$. In this paper, the LB films composed of the charged monolayers and the counter charged cyanine dyes are prepared on an ITO (indium tin oxide) electrode by the ion complex technique. Aggregation property of the cyanine dye is found to be controllable. Magnitude of the photocurrent is strongly affected by the aggregation structure of the cyanine dye.

\section{EXPERIMENTAL}

The double-chain amphiphiles 1,2 (Sogo Pharmaceutical) and cyanine dyes 3, 4 (Japanese Research Institute for Photosensitizing Dyes)were commercially available. Pressure-area isotherms were measured by a micro-processorcontrolled film balance with a Wilhelmy pressure sensing plate (USI System, FSD-50 film balance). Chloroform solution of the amphiphile was spread on the aqueous dye solution $(1 \mu \mathrm{M})$

Department of Biotechnology, Tokyo University of Agriculture \& Technology (Koganei, Tokyo 184, Japan)

Key Words: LB film, Photocurrent, J-aggregate at $20^{\circ} \mathrm{C}$. The complex monolayer was deposited on the hydrophilic surface of ITO electrodes and quartz plates by a normal vertical-dipping method. A 150-W xenon arc lamp (Ushio Electric) was used as a light source with a monochromator (Soma optics, S-10). The potential of the ITO electrode modified with the complex monolayer (effective area $1 \mathrm{~cm}^{2}$ ) was controlled with a potentiostat (Nikko Keisoku, NPGFZ-2501-A). The electrode soaked in an aqueous $0.1 \mathrm{M} \mathrm{KCl}$ solution, which was flashed with nitrogen gas before use, was irradiated in a nitrogen atmosphere. A platinum wire and a saturated calomel electrode (SCE) were used as a counter and reference electrode, respectively.

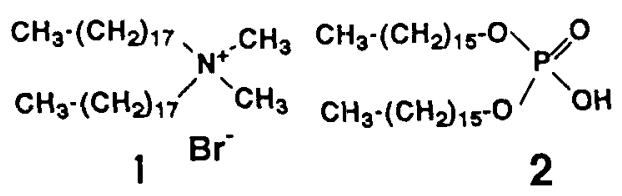<smiles>C/C(C=C1Sc2ccccc2N1C)=C\c1sc2ccccc2[n+]1C</smiles>

3<smiles>CCN1c2ccccc2SC1C(C)=Cc1sc2ccccc2[n+]1CC</smiles>

4

3 RESULTS AND DISCUSSION As the result of strong electrostatic 
interaction at the air-water interface, a complex monolayer has been formed when the cationic monolayer 1 was spread on the aqueous solution of the anionic cyanine dye 3 . An intense and sharp fluorescence at $618 \mathrm{~nm}$, which was attributed to the typical emission of the Jaggregate of dye $\mathbf{3}$, was observed from the complex monolayer on the water surface ${ }^{6}$. The complex monolayer is deposited on a solid substrate as a multilayer film. A Z-type LB film is prepared by a normal dipping technique at 30 $\mathrm{mN} / \mathrm{m}$. Average transfer ratio in the dipping-up and down process is 1.2 and 0.1 , respectively. A large band splitting at 500 and $610 \mathrm{~nm}$ in the LB film (Fig. 1a) suggests that the J-aggregate of the cyanine dye is kept in the multilayer film.

Complex formation between the anionic monolayer 2 and the cationic dye 4 is observed as a large expansion of the pressure-area isotherm. A Y-type L.B film is obtained from the complex of 2 and 4 . Although the chromophore of dye $\mathbf{4}$ is completely same as dye $\mathbf{3}$, absorption maximum of dye 4 locates at $500 \mathrm{~nm}$ (Fig. 1b). The large blue-shift of the absorption maximum indicates formation of dimer in the LB film.

The complex monolayer can be deposited on an ITO electrode, too. Sensitized cathodic photocurrent of the ITO electrode is generated by visible light irradiation. Large cathodic photocurrents of the n-type semiconductor electrodes sensitized by thin films of cyanine dyes ${ }^{7)}$ have been reported. Positive hole generated by photochemical oxidation of the sensitizer molecule is assumed to be a charge carrier for the cathodic photocurrent. The action spectra of the ITO electrodes modified with the complex LB films at $-0.4 \mathrm{~V}$ are shown in Fig. 1. Two peaks in the action spectrum of dye $\mathbf{3}$ are essentially the same as the absorption peaks. Although the complex LB film of dye 4 shows a extreme blue shift in the absorption spectrum, shape of the action spectrum is similar to that of dye 3. Quantum efficiency of dye 4 , however, is about forty times smaller than that of dye 3. These results indicate that the $\mathrm{J}$-aggregate sensitizes the cathodic photocurrent of the ITO electrode more effectively than that of the dimeric aggregate. Effective sensitization by the $J$-aggregates has been explained in terms of their high ability of exciton transfer ${ }^{7}$.
The ion-complex technique proves to be effective for preparation of cyanine dyecontaining LB films on solid substrates. A large difference in the sensitized photocurrent between the J-aggregate and the dimeric aggregate of the cyanine dyes are clearly demonstrated in this experiment.
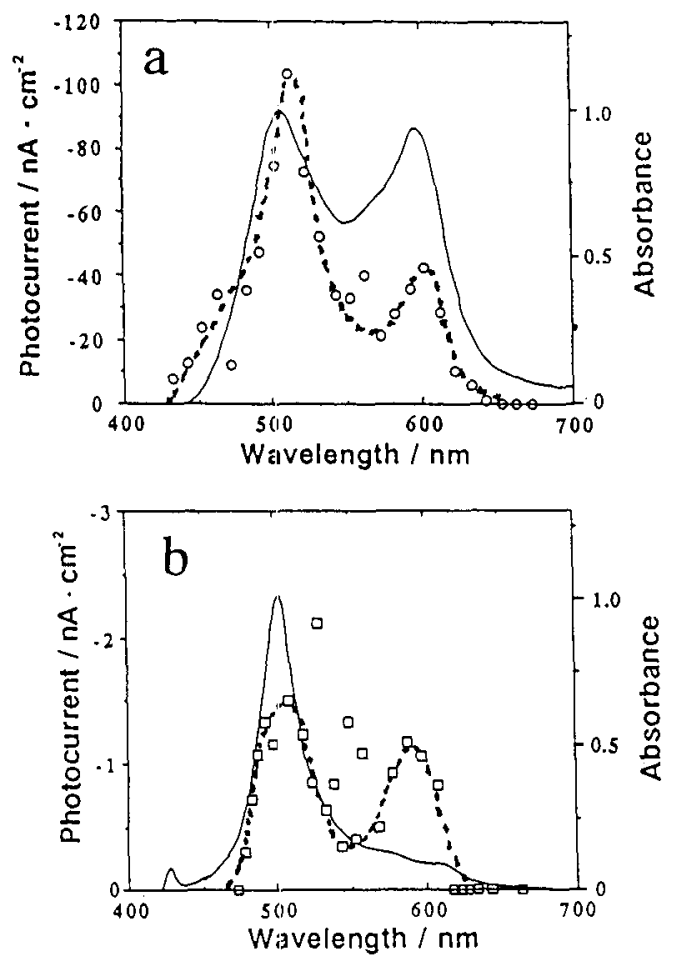

Fig. 1. Absorption (solid lines, 20 layers) and action spectra(5 layers) of LB films deposited at $30 \mathrm{mN} / \mathrm{m}$. a; dye $3, \mathrm{~b}$; dye 4.

\section{REFERENCES}

1) H.Kuhn and D.Möbius, Angew.Chem.Int . Ed. Engl.,10,620-637(1971).

2) T.Miyasaka, T.Watanabe, A.Fujishima and K.Honda, Nature,277,638(1979).

3) M.Shimomura and T.Kunitake, Thin Solid Films, 132,243(1985).

4) H.Hada, R.Hanawa, A.Haraguchi and Y.Yonezawa, J.Phys.Chem.,89,560(1985).

5) U.Lehmann, Thin Solod Films, 160, 257 (1988).

6) S.Kirstein, H.Mc̈hwald and M.Shimomura, Chem.Phys.Lett.,154,303(1989).

7) H.Hada, Y.Yonezawa and H.Inaba, Ber. Bunsenges.Phys.Chem.,85,425(1981). 